Gut, 1984, 25, 682-688

Clinical trial

\title{
Prospective randomised trial of early cytotoxic therapy for recurrent colorectal carcinoma detected by serum CEA
}

\author{
K R HINE AND P W DYKES \\ From the Department of Immunology, The Medical School, University of Birmingham, Birmingham, and \\ The General Hospital, Birmingham
}

SUMMARY Of 663 patients treated with radical surgery for colorectal cancer, 52 showed a progressive rise in serum carcinoembryonic antigen (CEA) with no other evidence of recurrent disease and were randomised in a prospective study of chemotherapy. Twenty six patients in the treatment group received $5 \mathrm{FU}$ and methyl $\mathrm{CCNU}$ from the time of randomisation and the remaining 26 controls were given further therapy only if there were clinical indications. All patients were followed for five years or until their death and all but one (control) developed clinical evidence of recurrence. Overall there was no significant difference between the two groups with respect to disease free interval and survival. Whereas the rise in CEA in controls was generally progressive, marked inflections on the CEA curves were seen in the majority of patients receiving early treatment. Eight of 26 treated patients showed a fall in CEA of greater than $20 \%$ two months after starting therapy. These patients had a median disease free interval of 90 weeks and a median survival of 107 weeks, these figures being longer than those of treated patients who did not show a fall in CEA and control patients. The serum CEA therefore appeared to give important prognostic information in patients receiving cytotoxic treatment. Early therapy was generally well tolerated.

The growth rate of solid tumours follows a Gompetz curve ${ }^{1}$ thus, as tumour mass increases, the growth rate slows as a result of several factors including inadequate circulation. As tumour cells are more sensitive to chemotherapy during the rapid growth phase with a high rate of DNA synthesis, treatment at this stage may be most efficacious. It has been shown that micrometastases are more sensitive to cytotoxic drugs than are larger tumour deposits. ${ }^{2}$ Previous reports have shown that a rise in the serum carcinoembryonic antigen (CEA) is often the first indication of recurrence after radical surgery for large bowel cancer. ${ }^{3-6}$ Furthermore, in the majority of patients the rise in CEA is indicative of disseminated disease. ${ }^{7}$ The introduction of cytotoxics at this early stage, when CEA alone indicates the presence of secondary disease, may allow for maximal benefit from currently available chemotherapy. In addition, the patient, being in general good health, may be

Address for correspondence: Dr P W Dykes, The General Hospital, Steelhouse Lane, Birmingham B4 6NH.

Received for publication 2 September 1983 better able to tolerate cytotoxic regimens. To test this hypothesis a prospective randomised trial was set up with patients in the treatment group receiving chemotherapy on the sole basis of a progressive rise in the serum CEA and controls being managed on clinical grounds.

\section{Methods}

PATIENTS

Six hundred and sixty three patients were followed with serial serum CEA measurements in addition to routine clinical surveillance after radical resection of colorectal carcinoma. Of these 114 showed a rise in the serum CEA before there was clinical evidence of recurrence. Further CEA measurements were made in these patients together with a programme of investigations (full blood count, erythrocyte sedimentation rate, liver function tests, barium enema, chest radiograph isotope and/or ultrasound liver scan, and bone scan and colonoscopy where indicated( and 52 fulfilled the criteria of at least two 
progressively rising CEA values greater than 35 $\mathrm{ng} / \mathrm{ml}$ and no other evidence of cancer. These patients were randomly allocated either to a control group (in which cytotoxics were not given except for clinical indications) or to a treatment group (in which chemotherapy was commenced immediately). Twenty six patients in the latter group were treated with intravenous 5-fluorouracil (5FU) $400 \mathrm{mg} / \mathrm{m}^{2}$ for five consecutive days and the course was repeated every five weeks. Alternate courses of 5FU were accompanied by a single oral dose of methyl CCNU $150 \mathrm{mg} / \mathrm{m}^{2}$. The 26 control patients initially received no specific therapy, although 10 later received chemotherapy for symptomatic disease. Both groups were reviewed at least once every three months and assessed for clinical evidence of recurrence. Prerandomisation blood tests were repeated at each attendance, particular attention was given to the time to clinical recurrence, CEA response, general well being and survival. All 52 patients were followed for five years or to the time of their death.

The two groups were well matched for age and sex distribution, interval between resection and randomisation and staging of the primary tumour (Table 1). Cytotoxic therapy was usually given on an outpatient basis with close monitoring of haematological indices.

Carcinoembryonic antigen was measured in the unextracted serum by a double antibody radioimmunoassay as developed by Egan et $a l^{8}$ and adapted by Laurence et al. ${ }^{9}$ The inter- and intraassay variation of the method was found to be less than $10 \%$. An upper limit of $15 \mathrm{ng} / \mathrm{ml}$ will include $99 \%$ of a normal population and in the present study a level of greater than $20 \mathrm{ng} / \mathrm{ml}$ was regarded as abnormal.

\section{Results}

Overall, there was no significant difference between the two groups with respect to disease free interval (the interval between randomisation and the first objective evidence of recurrence other than serum

Table 1 Comparison of treated and control patients

\begin{tabular}{lll}
\hline & $\begin{array}{l}\text { Treated } \\
(n=26)\end{array}$ & $\begin{array}{l}\text { Control } \\
(n=26)\end{array}$ \\
\hline $\begin{array}{l}\text { Mean ( } \pm \text { SEM) age at } \\
\text { randomisation (yr) }\end{array}$ & $61 \cdot 0 \pm 1 \cdot 9$ & $58 \cdot 7 \pm 2 \cdot 1$ \\
$\begin{array}{l}\text { Median interval between operation } \\
\quad \text { and randomisation (wks) }\end{array}$ & 63 & 59 \\
$\begin{array}{l}\text { Men:women } \\
\text { Dukes staging of }\end{array} \quad 18: 8$ & $15: 11$ \\
primary tumour & $\mathrm{B} 7$ & $\mathrm{~B} 10$ \\
\hline
\end{tabular}

CEA). The median disease free interval in the chemotherapy group was 36 weeks and in the control group 20 weeks ( $p>0 \cdot 1$ Mantel Haenzel test) (Fig. 1). Similarly there was no significant difference in postrandomisation survival between the two groups (treatment group 72 weeks; control group 70 weeks ( $p>0.5$ Mantel Haenzel test) (Fig. 2).

In one patient in the control group the rise in serum CEA probably gave false information about recurrent carcinoma. The decision to randomise was taken on two concentrations of CEA progressively rising from $41-63 \mathrm{ng} / \mathrm{ml}$. Two months after randomisation the CEA concentration had risen to $88 \mathrm{ng} / \mathrm{ml}$ but then it subsequently fell to normal levels and has remained so for five years. The patient remains clinically free of recurrent disease. The data relating to this patient have been included in the computations.

The decision to randomise was taken on a mean ( \pm SEM) serum CEA of $89.6 \pm 11.5 \mathrm{ng} / \mathrm{ml}$ in the treatment group and $80.9 \pm 7.7 \mathrm{ng} / \mathrm{ml}$ in the control group. The serum CEA was also measured at the time of randomisation and in the treatment group the mean was $151 \cdot 1 \pm 33.3 \mathrm{ng} / \mathrm{ml}$ and control group $123.2 \pm 17.7 \mathrm{ng} / \mathrm{ml}$. The CEA responses of all patients were classified according to the changes two months after randomisation. An ' $A$ ' response indicated a fall in the serum CEA of at least $20 \%$, a ' $\mathrm{B}$ ' response indicated a change of less than $20 \%$ and a ' $\mathrm{C}$ ' response a rise of $20 \%$ or more. The rise in serum CEA in control patients was generally progressive; thus 18 had a ' $C$ ' response and seven a ' $B$ ' response (Table 2). One patient died within two months of randomisation and was therefore unclassified. Among the patients who received early cytotoxic therapy, the rise in CEA was more variable; five showing a ' $C$ ' response, 12 a ' $B$ ' response and in eight the CEA fell by more than $20 \%$ (' $A$ ' response). One patient in the treatment group died within two months of randomisation and was not classified. The difference between treated and control patients in terms of CEA response was significant (Table $2 ; \mathrm{p}<0 \cdot 01$ ). In all the treated patients with ' $A$ ' and ' $B$ ' responses, the CEA has subsequently started to rise again, the mean duration of response being 36.4 weeks for ' $A$ ' responders and 14.0 weeks for ' $B$ ' responders. (The duration of response is taken as the time between randomisation and the stage at which the CEA rose to $20 \%$ above the pretreatment level.)

Although there was no significant difference overall in disease free interval between control and treatment groups, there was a marked difference in ' $A$ ' responders where the median disease free interval was 90 weeks compared with 31 weeks in treated ' $\mathrm{B}$ ' responders and 24 weeks in treated ' $\mathrm{C}$ ' 
Fig. 1 Disease free interval in 52 randomised patients.

(Life table survival analysis) control patients —; treated patients -...

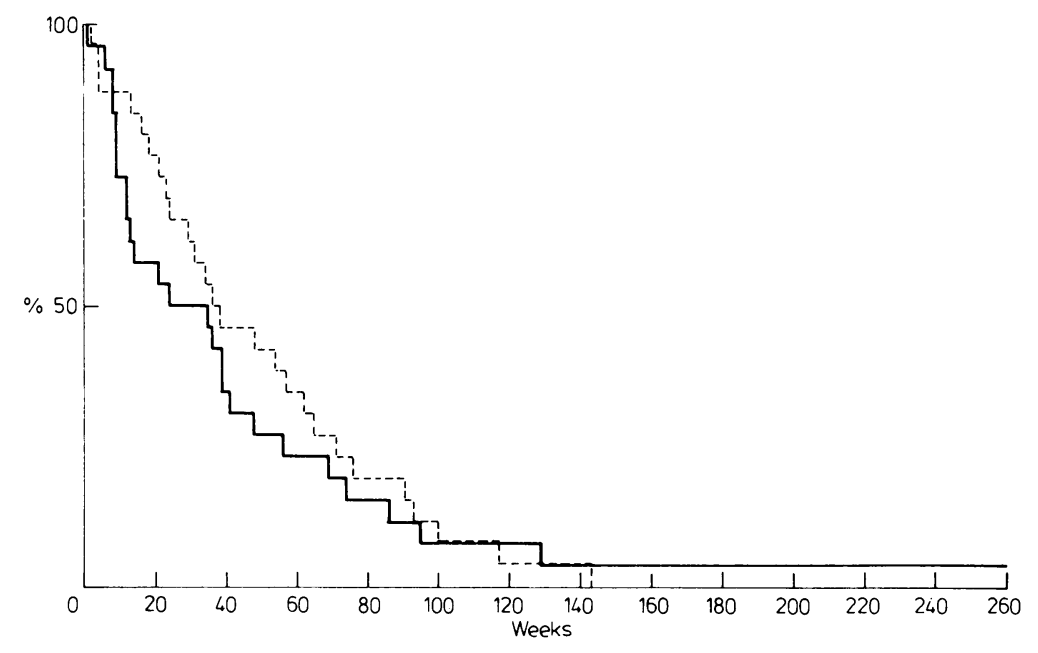

not significant $(\mathrm{p}<0 \cdot 05$, Mantel-Haenzel test).

Ten control patients were later treated with cytotoxics for symptomatic disease. Information regarding the CEA response to treatment was not available in seven of these as two died within two months of starting therapy and in five the appropriate samples for CEA testing were not obtained. Of the remaining three patients, two were ' $\mathrm{C}$ ' responders and one a ' $\mathrm{B}$ ' responder.

Cytotoxic therapy with 5FU and methyl CCNU was continued in the treatment group until there were clinical indications for an alteration in approach. In patients in whom therapy was stopped this was mainly because of an obvious increase in tumour burden despite treatment. Two patients, however (both 'A' responders), felt unable to
Fig. 2 Life table survival analysis for 52 randomised patients. Control patients treated patients - - -.

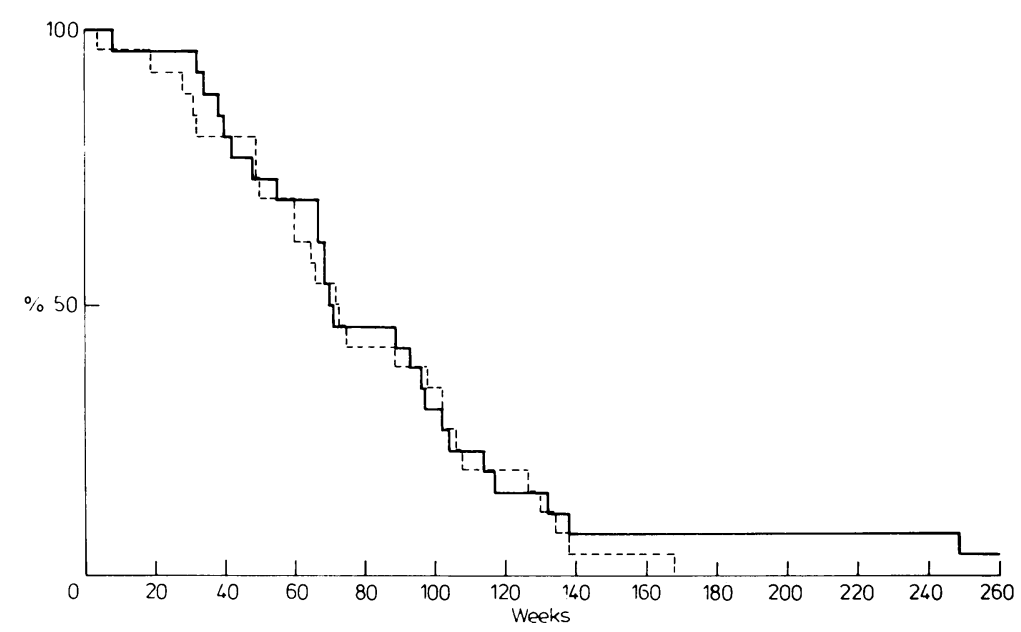


Table 2 CEA response at two months in randomised patients

\begin{tabular}{llrrl}
\hline & $A$ & $B$ & $C$ & Unclassified \\
\hline Treated & 8 & 12 & 5 & 1 \\
Control & 0 & 7 & 18 & 1 \\
\hline
\end{tabular}

tolerate the side effects of further therapy and cytotoxics were withdrawn although, at the time, both remained clinically free of disease, one after 10 and the other after seven courses of therapy. Bone marrow depression did not necessitate the complete withdrawal of treatment in any patient although several courses of therapy were postponed to allow more time for marrow recovery. Four patients were admitted to hospital with severe marrow depression after a course of therapy and of these, one required a platelet infusion and two required packed red cells. In one patient, severe leucopenia possibly contributed to his early unexpected death after admission to hospital for treatment of septicaemia, although necropsy revealed the primary cause of death as coronary artery disease. Alopecia was a major problem in only one treated patient and a wig was supplied until the hair regrew. Most patients complained of nausea and vomiting for between six and 24 hours after methyl CCNU and it was common for patients to feel generally 'off-colour' for about 10 days in association with each course of injections. Several patients continued with full-time occupations throughout the treatment cycle, however, and the majority felt the side effects were tolerable.

\section{Discussion}

These results show that it is possible to produce temporary inflections on the CEA curves of the majority of patients undergoing cytotoxic therapy for recurrent colorectal cancer. A general correlation between CEA and clinical response to chemotherapy has been reported, ${ }^{10-14}$ but in the present study clinical benefit was only derived in those patients who showed a marked fall in the serum CEA at two months.

The 'CEA response' in this study has been defined in terms of a percentage change in serum CEA two months after randomisation. A $20 \%$ change is outside the intra- and inter-assay variation of the laboratory method ${ }^{15}$ and the two month period avoided confusion caused by a transient rise in CEA seen in some patients after giving cytotoxics which was presumably the result of cell-necrosis. Nitrosoureas have been reported as having a non-specific depressant effect on CEA levels ${ }^{16}$ and in the present study a full two months elapsed between the dose of methyl CCNU and the collection of the comparison sample for CEA. Thus although the 'CEA response' as defined does not completely reflect changes in the CEA curve as comparison is made between only two points, it is a simple and practical index and appears to give useful prognostic information.

Martin and his colleagues adopted an aggressive surgical approach in patients with a significant rise in serum CEA ${ }^{1718}$ and of 60 second look procedures, 23 patients $(39 \%)$ remain disease free the longest survival being over seven years. ${ }^{19}$ Localised anastomotic recurrences and metachronous tumours, however, are the only two types of lesion
Fig. 3 Disease free interval in 52 randomised patients grouped according to their $C E A$ response two months after randomisation. (Life table survival analysis) treated ' $A$ ' responders $\bullet-$; treated ' $B$ ' responders $\mathrm{O}-\mathrm{O}$; treated ' $C$ ' responders $\mathbf{\square -}-\mathbf{-}$; control ' $B$ ' responders $\triangle \longrightarrow$ 'C' responders $\square$ - - - $\square$.

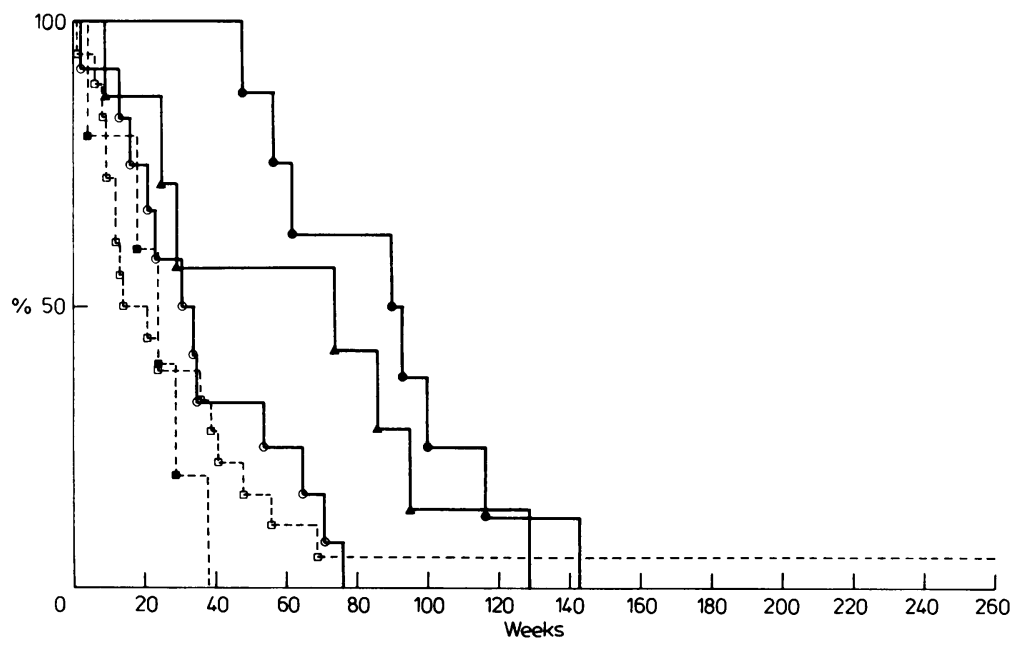


Fig. 4 Life table survival analysis for 52 randomised patients grouped according to their CEA response two months after randomisation. Treated A responders $\bullet-\bullet$; treated ' $B$ ' responders $\mathrm{O}-\mathrm{O}$ : treated 'C' responders - - - - control ' $B$ ' responders $\triangle \longrightarrow$ - control 'C' responders $\square .-. \square$.

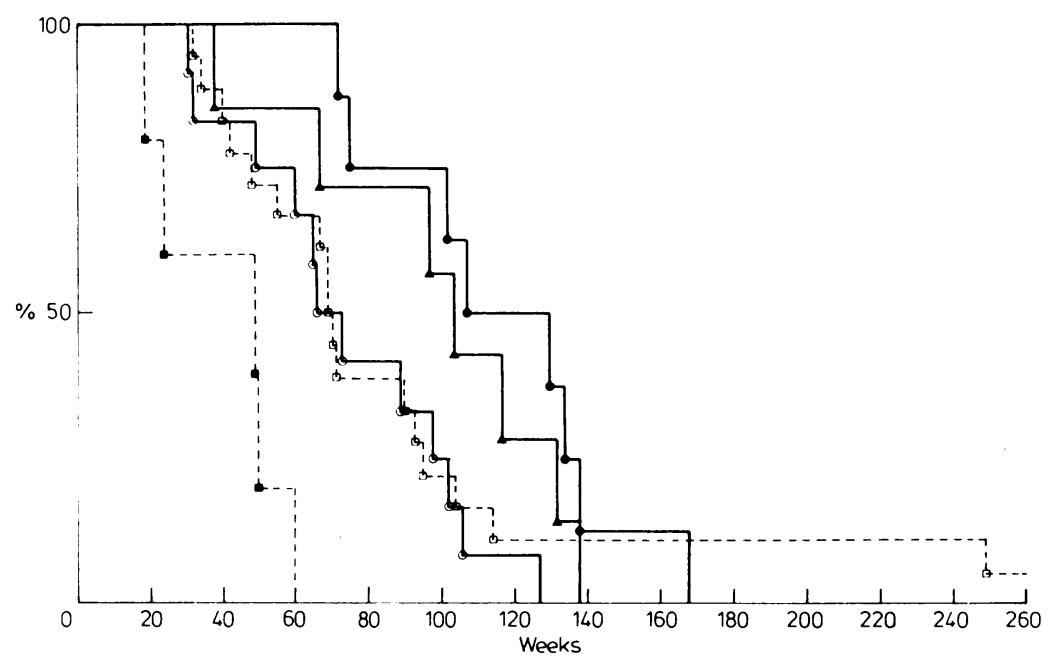

which would generally be regarded as respectable. Serum CEA is a very poor index of such localised disease $^{7}$ and some patients operated on by Martin and his colleagues had extensive dissemination of their malignancy ${ }^{21}$ which would not generally be regarded as operable. These patients were given additional systemic therapy ${ }^{20}$ thus it is difficult from their papers to ascertain the value of surgery alone. Other centres adopting a similar approach have failed to obtain comparable figures ${ }^{2-25}$ and the results of the current United Kingdom trial of second look surgery (personal communication) are awaited with interest.

The overall response to cytotoxic therapy in the present study was disappointing. The choice of drugs was based on the early work of Moertel et $a^{26}$ which suggested that $43.5 \%$ of patients with disseminated colorectal cancer responded to $5 \mathrm{FU}$, methyl CCNU and vincristine. This response rate was not confirmed by later studies ${ }^{27}$ and although there have been reports that combinations of other agents such as mitomycin-C, ${ }^{28}$ razoxane, ${ }^{29}$ adriamycin and cis platin $^{30}$ are marginally better, there remains an urgent need for a truly effective drug regime in colorectal cancer. If such agents were discovered then the early detection of recurrence by studying tumour associated antigens in the serum would be of greater importance and the introduction of chemotherapy may elicit a more significant response than has been shown in this trial.

Of the randomised patients. those showing an ' $A$ ' response to chemotherapy had a median disease free interval survival longer than other treated patients and controls. On the other hand six control patients had disease free interval in excess of 52 weeks and six survived for more than 104 weeks after random- isation. Apart from the clinical outcome, there are no other data to separate these individuals from the majority of the control patients but when taken as a group the disease free interval and survival figures are comparable with those of ' $A$ ' responders. This raises the possibility that an ' $A$ ' response to early chemotherapy is merely a sophisticated method of selecting those patients who would do well irrespective of therapy. Such a possibility cannot be disproved from the present data, although there are no theoretical grounds for supposing that those patients with a slow rate of tumour growth are more likely to have a better response to chemotherapy.

At the other extreme, the ' $\mathrm{C}$ ' responders to treatment fared particularly badly and it is possible that chemotherapy impaired their length and quality of life. In those patients in whom CEA continues to rise after starting cytotoxics it may be more appropriate to either stop or change therapy. This question has not been addressed in the present trial and could be the subject of further clinical study. Nevertheless, changes in CEA do appear to give important prognostic information after the introduction of cytotoxic therapy.

\section{Conclusion}

While the rise in CEA in control patients was progressive, marked inflections were commonly produced in the CEA curves of patients receiving therapy.

Patients who showed a fall in CEA of at least $20 \%$ two months after the start of treatment (' $A$ ' responders) had a disease free interval and survival which were longer than those of either controls or other treated patients. Changes in CEA after 
starting therapy therefore appeared to give important prognostic information.

The possibility should be considered that there is a group of patients ('C' responders) who might have been adversely affected by the drugs.

The response rate to chemotherapy in disseminated colorectal cancer was poor even when treatment was given at the earliest indication of recurrence as evidenced by a rising serum CEA. There is a need for more effective cytotoxic agents for this condition.

We are grateful to those surgeons who contributed cases to this study. The work was supported by a grant from the Medical Research Council.

\section{References}

1 Frei EF. Kinetic parameters and growth curves for experimental tumour systems. Cancer Chemother Rep 1970; 54: 143-74.

2 Sugarbaker PH, Skarin AT, Zamcheck N. Patterns of serial CEA assays and their clinical use in managements of colorectal cancer. J Surg Oncol 1976; 8: 523-37.

3 Sorokin JJ, Sugarbaker PH, Zamcheck N, Pisick M, Kupchick NZ, Moore FD. Serial carcinoembryonic antigen assays. Use in detection of cancer recurrence. J Am Med Ass 1974; 228: 49-53.

4 Mackay AM, Patel S, Canter S et al. Role of serial plasma CEA assays in detection of recurrent and metastatic colorectal carcinomas. Br Med J 1974; 4: 383-5.

5 Booth SN, Jamieson GC, King JPG, Leonard J, Oates GD, Dykes PW. Carcinoembryonic antigen in management of colorectal carcinoma. Br Med J 1974; 4: 183-7.

6 Mach JP, Jaeger PH, Bertholet MM, Ruegsegger C-H, Loosli RM, Pettavel J. Detection of recurrence of large bowel carcinoma by radioimmunoassay of circulating carcinoembryonic antigen (CEA). Lancet 1974; 2: 535-40.

7 Hine KR, Dykes PW. Serum CEA testing in the post-operative surveillance of colorectal carcinoma. $\mathrm{Br}$ $J$ Cancer 1984. (In press)

8 Egan ML, Lautenschleger JT, Coligan JE, Todd CW. Radioimmunoassay of carcinoembryonic antigen. Immunochemistry 1972; 9: 289-99.

9 Laurence DJR, Stevens U, Bettelheim R et al. Role of plasma carcinoembryonic antigen in diagnosis of gastrointestinal mammary, and bronchial carcinoma. Br Med J 1972; 3: 605-9.

10 Mulcare $\mathrm{R}$, Logerfo $\mathrm{P}$. Tumour associated antigen in the chemotherapy of solid tumors. J Surg Oncol 1972; 4: $407-17$

11 Holyoke D, Reynoso G, Chu TM. Carcinoembryonic antigen (CEA) in patients with carcinoma of the digestive tract. Ann Surg 1972; 176: 559-64.
12 Skarin AT, Delwiche R, Zamcheck N, Lokich JJ, Frei E. Carcinoembryonic antigen: clinical correlation with chemotherapy for metastatic gastrointestinal cancer. Cancer 1974; 33: 1239-45.

13 Ravry M, Moertel CG, Schutt AJ, Go VLW. Usefulness of serial serum carcinoembryonic antigen (CEA) determinations during anti-cancer therapy or long-term follow-up of gastrointestinal carcinoma. Cancer 1974; 34: $1230-4$.

14 Mayer RJ, Garnick MB, Steele GD, Zamcheck N. Carcinoembryonic antigen (CEA) as a monitor of chemotherapy in disseminated colorectal cancer. Cancer 1978; 42: 1428-33.

15 Booth SN. An evaluation of carcinoembryonic antigen in clinical medicine. MD Thesis; University of Birmingham, 1974.

16 Herrera MA, Chu TM, Holyoke ED, Mittelman A. CEA monitoring of palliative treatment for colorectal carcinoma. Ann Surg 1977; 185: 23-30.

17 Martin EW, James KK, Hurtubise PE, Catalano P, Minton JP. The use of CEA as an early indicator for gastrointestinal tumor recurrence and second-look procedures. Cancer 1977; 39: 446-9.

18 Minton JP, James KK, Hurtubise PE, Rinker L, Joyce S, Martin EW. The use of serial carcinoembryonic antigen determinations to predict recurrence of carcinoma of the colon and the time for a second-look operation. Surg Gynec Obstet 1978; 147: 208-10.

19 Martin EW, Cooperman M, Carey LC, Minton JP. Sixty second-look procedures indicated primarily by rise in serial carcinoembryonic antigen. J Surg Res 1980; 28: 289-94.

20 Minton JP, Martin EW. The use of serial CEA determinations to predict recurrence of colon cancer and when to do a second-look operation. Cancer 1978; 42: 1422-7.

21 Evans JT, Mittelman A, Chu M, Holyoke ED. Preand post-operative uses of CEA. Cancer 1978; 42: 1419-21.

22 Nicholson JR, Aust JC. Rising carcinoembryonic antigen titres in colorectal carcinoma: an indication for the second-look procedure. Dis Colon Rectum 1978; 21: $163-4$.

23 Staab HJ, Anderer A, Stumpf E, Fischer R. Carcinoembryonic antigen follow-up and selection of patients for second-look operation in management of gastrointestinal carcinoma. J Surg Oncol 1978; 10: 273-82.

24 Beatty JD, Romero C, Brown PW, Lawrence W, Terz JJ. Clinical value of carcinoembryonic antigen; diagnosis, prognosis and follow-up of patients with cancer. Arch Surg 1979; 114: 563-7.

25 Cohen AM, Wood WC. Carcinoembryonic antigen levels as an indicator for reoperation in patients with carcinoma of the colon and rectum. Surg Gynecol Obstet 1979; 149: 22-6.

26 Moertel CG, Schutt AJ, Hahn RG, Reitemeir RJ. Therapy of advanced gastrointestinal cancer with a combination of 5FU, methyl CCNU and vincristine. J Natl Cancer Inst 1975; 54: 69-71.

27 Buroker T, Kim PN, Groppe C et al. 5FU Infusion with mitomycin-C versus $5 \mathrm{FU}$ infusion with methyl CCNU in the treatment of advanced colon cancer. Cancer 
1978; 42: 1228-33.

28 Crooke ST, Bradner WT. Mitomycin-C: A review. Cancer Treat Rev 1976; 3: 121-39.

29 Marciniak TA, Moertel CG, Schutt AJ, Hahn RG, Reitemeier R. Phase II study of ICRF-159 (NSC.
129943) in advanced colorectal cancer. Cancer Chemother Rep 1975; 59: 761-3.

30 Schein PS. Communication to XI International Congress of Gastroenterology, Hamburg 1980. Hepatogastroenterol (Stutt) 1980. 